\title{
AVALIAÇÃo DO TIPO DE GÁS E DA PRESSÃO INICIAL NO TRATAMENTO HIDROTÉRMICO DA PALHA DE CANA-DE- AÇÚCAR PARA A PRODUÇÃO DE ETANOL CELULÓSICO.
}

\author{
OLIVIERI, R.R.B ${ }^{1}$, BON, E.P.S ${ }^{1}$ \\ ${ }^{1}$ Universidade Federal do Rio de Janeiro, Departamento de Bioquímica do Instituto de Química \\ E-mail para contato: rodrigo.eq@gmail.com
}

\begin{abstract}
RESUMO - Os bicombustíveis têm se mostrado como as fontes energéticas mais viáveis em relação às outras fontes renováveis e poderiam futuramente, substituir o uso do petróleo. No Brasil, o etanol celulósico é apontado como um dos potenciais biocombustíveis a ser produzido em escala industrial em virtude da alta oferta de cana-deaçúcar. Entretanto ainda permanecem questões relacionadas à seleção da biomassa, aos tipos de pré-tratamento que serão empregados bem como suas condições de processo, e o custo das enzimas celulolíticas, que é outro fator importante por possuir um forte impacto no custo do processamento das biomassas lignocelulósica para a comercialização do etanol celulósico. A palha e o bagaço de cana são resíduos com potencial para a implementação industrial da produção de etanol celulósico associada à cogeração de energia nas usinas. A palha de cana-de-açúcar pode ser utilizada também como agente de proteção das culturas de cana. A biomassa lignocelulósica ao passar pelas etapas de prétratamento, hidrólise enzimática, fermentação alcoólica e destilação, pode dar origem ao etanol celulósico, oriundo da celulose presente nestes materiais. Este trabalho visa avaliar parâmetros relacionados ao tratamento hidrotérmico como o tipo de gás de pressurização (nitrogênio, ar sintético e gás carbônico) e a pressão inicial (5-20 bar) com o intuito de beneficiar a hidrólise enzimática da palha de cana e/ou reduzir o custo com as enzimas na etapa de hidrólise enzimática.
\end{abstract}

\section{INTRODUÇÃO}

Os materiais lignocelulósicos são os compostos orgânicos mais abundantes na biosfera terrestre, representando $50 \%$ da biomassa terrestre, segundo Sarko (1997). Dentre os resíduos agroindustriais de composição lignocelulósica de maior importância destacam- se: bagaço e palha de cana-de-açúcar; sabugo e palha de milho; palhas de trigo e arroz, restos de madeira processada e lixo com base em papel.

O bagaço de cana e palha de cana são produzidos em grandes quantidades pelas usinas de açúcar e álcool no Brasil (Martínez et al., 2003; Hernandéz-Sallas et al., 2009). Segundo Pandey et al., (2000) Cerca de 50\% deste resíduo é utilizado em destilarias 


\section{9 a 22 de outubro de 2014 \\ Florianópolis/SC}

como fonte de energia; enquanto o restante é acumulado. Portanto, devido a disponibilidade do bagaço de cana e da palha como resíduos da agroindústria da cana, que oferece vantagens econômicas, ambientais e estratégicas, há um grande interesse no desenvolvimento das tecnologias de produção de combustíveis e produtos químicos, a partir destes materiais (Adsul et. al., 2004).

As frações, celulósica e hemicelulósica do bagaço e da palha de cana, podem ser hidrolisadas por celulases e hemicelulases gerando principalmente glicose e xilose, que são açucares passíveis de serem fermentados a etanol. O microrganismo de eleição para fermentar glicose é a levedura Saccharomyces cerevisiae, que, entretanto, não metaboliza a xilose a etanol (Cheng et al., 2008). A estrutura nativa da parede celular vegetal, que é o principal componente dos materiais lignocelulósicos apresenta uma estrutura supramolecular recalcitrante à degradação por agentes biológicos. Assim, estes materiais devem ser tratados por processos físicos, químicos ou biológicos visando alterar a sua estrutura nativa e diminuir a recalcitrância á hidrólise enzimática. Embora a composição química dos produtos e subprodutos do pré-tratamento variem, de acordo com a natureza do processo, existem fatores que afetam a eficiência da hidrólise da celulose: a porosidade do material (área de superfície acessível), a cristalinidade das fibras de celulose e o teor de lignina e hemicelulose presente no material que dificultam o acesso das enzimas as fibras de celulose, impedindo a hidrólise de 100\% da celulose (Mc Millan, 1994). A remoção ou redução dos teores de lignina e hemicelulose em conjunto com a diminuição da cristalinidade através de processos de pré-tratamento podem favorecer significativamente a etapa de hidrólise. A hidrólise enzimática da hemicelulose não apresenta dificuldades cinéticas ou de rendimento em função da sua natureza amorfa.

\subsection{Pré-tratamentos de biomassa}

Inúmeras estratégias de pré-tratamento vêm sendo desenvolvidas com o objetivo de aumentar a reatividade da celulose e assim consequentemente aumentar o rendimento de açúcares fermentáveis na etapa de sacarificação enzimática. Os objetivos típicos dos prétratamentos estudados são: (1) produção de compostos digestíveis que beneficiem o rendimento de hidrólise enzimática; (2) evitar a degradação de açúcares (especialmente as pentoses) incluindo aquelas oriundas da fração hemicelulósica; (3) minimizar a formação de inibidores para as etapas de fermentação subsequentes; (4) recuperação da lignina para formação de subprodutos e (5) ter um custo operacional efetivo utilizando reatores de tamanho moderado que minimizem a demanda por calor e energia. Os tipos de pré-tratamento geralmente são classificados como: físicos, químicos, físico-químicos ou biológicos (Brodeur et al., 2011).

Pré-tratamento hidrotérmico: O Hot compressed water (HCW), também chamado por alguns autores como Liquid Hot Water (LHW) é um tipo de tratamento hidrotérmico que não utiliza nenhum tipo de reagente químico e não é necessária a descompressão rápida. Neste tratamento, a pressão e aplicada para manter a água no estado líquido a temperaturas elevadas (160- $\left.240^{\circ} \mathrm{C}\right)$. O principal objetivo deste tratamento é a solubilização da hemicelulose para 
tornar a celulose mais acessível, evitando a formação de inibidores. A fração liquida gerada ao final deste tratamento pode ser filtrada dando origem a duas correntes, uma delas rica em celulose (resíduo sólido) e outra rica em açúcares derivados da hemicelulose. Através deste método, a lignina é parcialmente solubilizada e despolimerizada, entretanto a total deslignificação não é possível somente ao utilizar água quente, devido à recondensação de alguns componentes solúveis presentes na lignina. Em geral este tipo de tratamento é atrativo do ponto de vista econômico por não requerer catalisadores, utilizar reatores com baixo custo de construção, por possuir baixo potencial de corrosão e pelo aproveitamento energético, uma vez que o calor gerado pelo o tratamento pode ser utilizado em outras correntes através do emprego de trocadores de calor (Alvira, et al., 2010).

Este trabalho visa avaliar parâmetros relacionados ao tratamento hidrotérmico, como a pressão inicial do sistema e o tipo de gás utilizado, a fim de beneficiar a hidrólise enzimática da palha de cana-de-açúcar visando a otimização técnico-científica e econômica do processo.

\section{Materiais e métodos}

\subsection{Matéria-prima}

A palha de cana-de-açúcar foi gentilmente cedida pelo Complexo Bioenergético Itarumã S.A. (Goiás, Brasil - http://www.usinaitaruma.com.br). Este material foi seco à temperatura ambiente, pré-moído em moinho de facas SM-300 (Retsch, Alemanha) e peneirado de forma a selecionar partículas menores que $2 \mathrm{~mm}$. Para a determinação do teor de umidade do material peneirado foi utilizando o analisador de umidade modelo IV-3000 (Indústria e Comércio Eletro Eletrônica Gehaka, São Paulo, Brasil).

\subsection{Tratamento hidrotérmico}

Os ensaios de pré-tratamento hidrotérmico foram realizados utilizando um reator de aço inox com volume total de $1 \mathrm{~L}$ e volume útil de $300 \mathrm{~mL}$ (Parr 4520, PARR Instrument Company, Moline, IL, E.U.A). O reator foi alimentado com $30 \mathrm{~g}$ de biomassa seca (partículas menores que $2 \mathrm{~mm}$ ) suspensa em $300 \mathrm{~mL}$ de água (100 g/L), a mistura foi homogeneizada e para a pressurização do sistema, foram utilizados diferentes tipos de gases, como, Nitrogênio UP, Ar sintético UP e $\mathrm{CO}_{2}$ industrial, variando a pressão de 0 a 20 bar e mantendo a agitação de $100 \mathrm{RPM}$, a temperatura em $165^{\circ} \mathrm{C}$ durante 25 minutos para todas as condições testadas. Experimentos controles sem pressão inicial e/ou somente com a purga de cada gás foram realizados afim de comparar o efeito de cada um deles sobre a biomassa.

A fração sólida gerada no pré-tratamento foi lavada com $600 \mathrm{~mL}$ de água deionizada antes da realização dos ensaios de hidrólise enzimática. Já a fração líquida gerada nos ensaios de pré-tratamento foi quantificada em termos de inibidores como, furfural, hidroximetil furfural (HMF) e ácido acético. 


\subsection{Hidrólise enzimática}

Os ensaios de sacarificação enzimática foram realizados visando avaliar a eficiência dos pré-tratamentos como facilitadores da hidrólise da celulose contida na biomassa da canade-açúcar. As misturas reacionais apresentando $10 \mathrm{~g}$ de substrato em um volume total de $100 \mathrm{~mL}$ foram conduzidos à $50^{\circ} \mathrm{C}$ por até $72 \mathrm{~h}$ em $\mathrm{pH}$ inicial 4,8 (tampão citrato de sódio $50 \mathrm{mM})$ e 200 RPM. A carga de enzima correspondeu a 10 FPU/g de biomassa, sendo utilizada a enzima comercial Power Cell (Prozyn, São Paulo, Brasil). Amostras foram retiradas em $0 \mathrm{~h}, 48 \mathrm{~h}$ e $72 \mathrm{~h}$ para análise dos açúcares liberados.

\subsection{Quantificação de produtos por cromatografia líquida de alta eficiência (CLAE)}

Os açúcares produzidos na etapa de hidrólise enzimática foram quantificados por um sistema de CLAE (Ultimate 3000, Thermo Scientific, E.U.A) equipado com uma coluna Aminex HPX-87P (7.8 mm I.D. $\times 30 \mathrm{~cm}$, BioRad, E.U.A) e um detector de índice de refração, trabalhando à $80^{\circ} \mathrm{C}$ com fluxo de $1,0 \mathrm{~mL}$ de água por minuto. Inibidores como o furfural, 5hidroximetilfurfural (HMF) e ácido acético, também foram analisados por um sistema de CLAE (Elite La Chrom, Hitachi, Japão). Neste últi mo caso, foi utilizada a coluna, Aminex HPX-87H (7.8 mm I.D. $\times 30 \mathrm{~cm}$, BioRad, E.U.A), à temperatura de $60{ }^{\circ} \mathrm{C}$ utilizando $1 \mathrm{mM}$ de ácido sulfúrico $\left(\mathrm{H}_{2} \mathrm{SO}_{4}\right)$ como eluente a um fluxo de $0,6 \mathrm{~mL}$ por minuto.

\section{RESULTADOS}

\subsection{Pré-tratamentos com $\mathrm{N}_{2}$}

A figura 1 apresenta os resultados após $72 \mathrm{~h}$ de hidrólise enzimática para todos os prétratamentos realizados utilizando nitrogênio como gás de pressurização, nas pressões de 5 bar, 10 bar, 15 bar e 20 bar. Adicionalmente aos ensaios acima mencionados foram testados 3 controles comparativos: 1) Para o material sem tratamento; 2) Para o material sem purga de $\mathrm{N}_{2}$ e sem pressão inicial e 3) Para o material com purga de $\mathrm{N}_{2}$ e sem pressão inicial. 


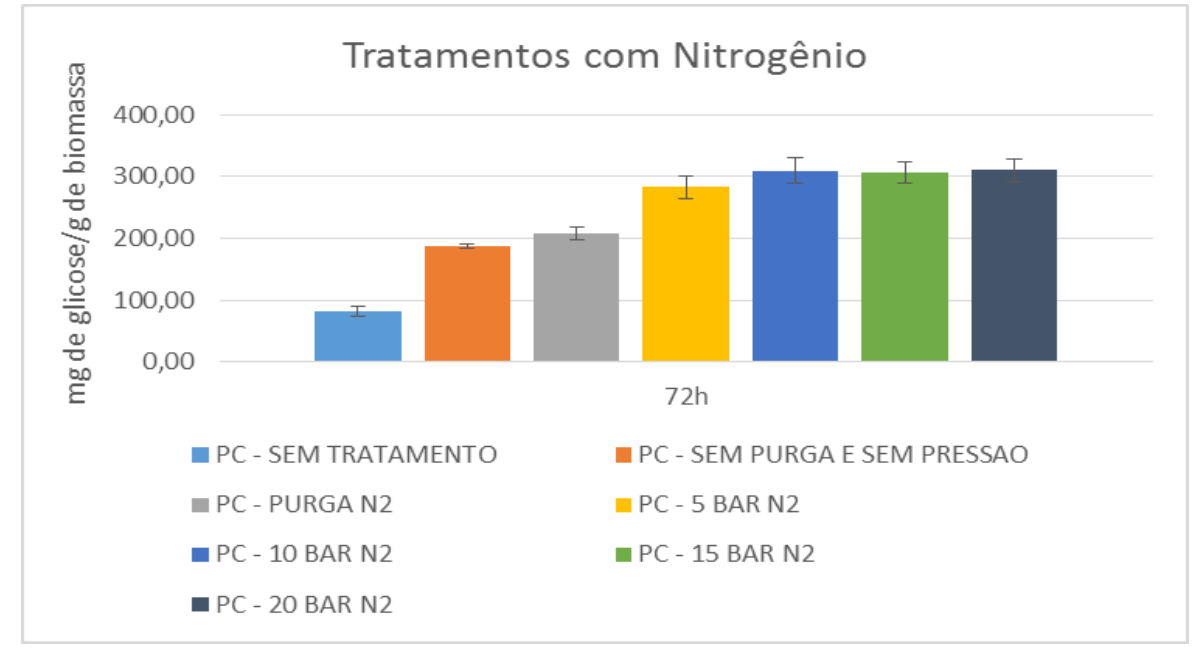

Figura 1 - Resultados de recuperação de glicose após 72h de hidrólise enzimática para ensaios de pré-tratamento utilizando nitrogênio ultra puro como gás de pressurização.

A partir dos resultados apresentados na figura 1 é possível observar que os níveis de glicose recuperados para pressões iguais ou superiores a 10 bar são muito próximos, indicando uma saturação da hidrólise enzimática ao recuperar aproximadamente $310 \mathrm{mg}$ de glicose por grama de biomassa. Considerando que a palha de cana possui aproximadamente $38 \%$ de celulose em sua composição química, pode-se estimar que o rendimento de hidrólise nas melhores condições de tratamento ao utilizar nitrogênio como gás de pressurização é da ordem de $74 \%$. Para palha de cana sem tratamento foi possível recuperar $81 \mathrm{mg}$ de glicose/g de biomassa, o que correponde a aproximadamente $19 \%$ de rendimento. Para o experimento sem purga e sem pressão foi possível recuperar $187 \mathrm{mg}$ de glicose/ $\mathrm{g}$ de biomassa, o que corresponde a aproximadamente $45 \%$ de rendimento. E finalmente ao fazer somente a purga com nitrogênio foi possível recuperar $208 \mathrm{mg}$ de glicose/ g de biomassa, o que corresponde a 50\% de rendimento.

\subsection{Pré-tratamentos com Ar sintético}

A figura 2 apresenta os resultados após 72h de hidrólise enzimática para todos os prétratamentos realizados utilizando ar sintético ultra puro como gás de pressurização, nas pressões de 5 bar, 10 bar, 15 bar e 20 bar. Adicionalmente aos ensaios acima mencionados foram testados 3 controles comparativos: 1) Para o material sem tratamento; 2) Para o material sem purga de ar sintético e sem pressão inicial e 3) Para o material com purga de ar sintético e sem pressão inicial. 


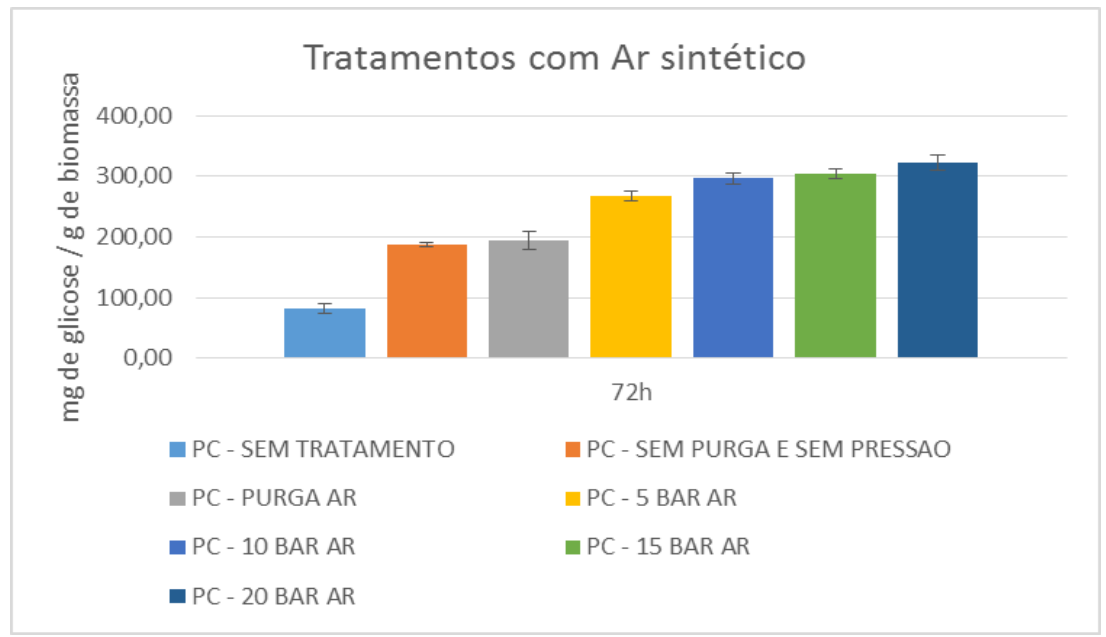

Figura 2 - Resultados de recuperação de glicose após 72h de hidrólise enzimática para ensaios de pré-tratamento utilizando ar sintético ultra puro como gás de pressurização.

A partir dos resultados apresentados na figura 2 é possível observar que os níveis de glicose recuperados para pressões iguais ou superiores a 10 bar, similarmente aos resultados obtidos com ar sintético, os resultados de recuperação de glicose foram muito próximos, indicando uma saturação da hidrólise enzimática ao recuperar aproximadamente $323 \mathrm{mg}$ de glicose por grama de biomassa. Considerando que a palha de cana possui aproximadamente $38 \%$ de celulose em sua composição química, pode-se estimar que o rendimento de hidrólise nas melhores condições de tratamento ao utilizar ar sintético como gás de pressurização é da ordem de $77 \%$. Ao fazer somente a purga com ar sintético foi possível recuperar $195 \mathrm{mg}$ de glicose/ g de biomassa, o que corresponde a $47 \%$ de rendimento.

\subsection{Pré-tratamentos com $\mathrm{CO}_{2}$}

A figura 3 apresenta os resultados após $72 \mathrm{~h}$ de hidrólise enzimática para todos os prétratamentos realizados utilizando $\mathrm{CO}_{2}$ industrial como gás de pressurização, nas pressões de 5 bar, 10 bar, 15 bar e 20 bar. Adicionalmente aos ensaios acima mencionados foram testados 3 controles comparativos: 1) Para o material sem tratamento; 2) Para o material sem purga de ar sintético e sem pressão inicial e 3) Para o material com purga de $\mathrm{CO}_{2}$ e sem pressão inicial. 


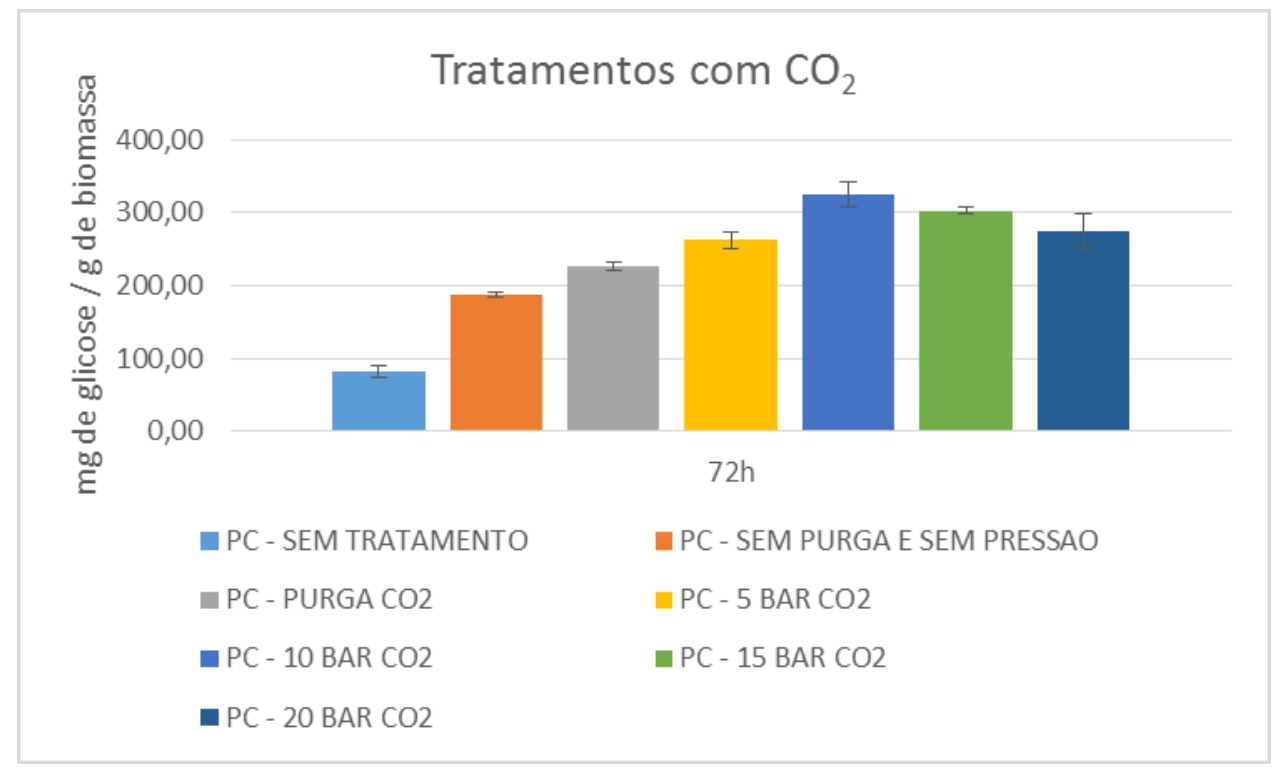

Figura 3 - Resultados de recuperação de glicose após 72h de hidrólise enzimática para ensaios de pré-tratamento utilizando $\mathrm{CO}_{2}$ industrial como gás de pressurização.

A partir dos resultados apresentados na figura 3 é possível observar que os níveis de glicose recuperados para uma pressão de 10 bar foram os maiores, quando comparados aos resultados com pressões superiores ou inferiores. Indicando que para pressões superiores a 10 bar podem sugerir uma degradação da celulose do material devido ao caráter oxidante do $\mathrm{CO}_{2}$. Para a pressão de 10 bar de CO2, foi possível recuperar aproximadamente $324 \mathrm{mg}$ de glicose por grama de biomassa. Considerando que a palha de cana possui aproximadamente $38 \%$ de celulose em sua composição química, pode-se estimar que o rendimento de hidrólise utiizando 10 bar de pressão de $\mathrm{CO}_{2}$ é da ordem de $78 \%$. Ao fazer somente a purga com $\mathrm{CO}_{2}$ foi possível recuperar $226 \mathrm{mg}$ de glicose/g de biomassa, o que corresponde a 54\% de rendimento.

\subsection{Formação de inibidores de fermentação}

A fim de confirmar a melhor condição de pré-tratamento hidrotérmico em termos do gás de pressurização e da pressão inicial de tratamento, é necessário também, avaliar em conjunto com a hidrólise enzimática, a formação de produtos inibitórios durante o tratamento. Inibidores como HMF e furfural, que são provenientes da desidratação da glicose e xilose, são extremamente tóxicos para as leveduras que promovem a fermentação alcoólica. Além disso a formação de ácido acético também acontece devido a auto hidrólise da biomassa durante os diversos pré-tratamentos, como consequência da presença de terminais acetato presentes na estrutura nativa da biomassa de cana.

Ao avaliar a formação de HMF para os 3 gases testados em diferentes pressões, não foi possível identificar um perfil diferenciado pois em todas as condições testadas, os níveis de HMF liberados na fase líquida foram da ordem de $0,2 \mathrm{~g} / \mathrm{L}$. 


\section{9 a 22 de outubro de 2014 \\ Florianópolis/SC}

Já os níveis de furfural e ácido acético gerados comparando os 3 gases a 10 bar de pressão foram superiores para $\mathrm{CO} 2(1,0 \mathrm{~g} / \mathrm{L}$ e $1,2 \mathrm{~g} / \mathrm{L}$, respectivamente $)$ seguidos pelo ar sintético $\left(0,6 \mathrm{~g} / \mathrm{L}\right.$ e $0,9 \mathrm{~g} / \mathrm{L}$, respectivamente). Para os tratamentos com 10 bar de $\mathrm{N}_{2}$ foram gerados $0,3 \mathrm{~g} / \mathrm{L}$ de furfural e $0,5 \mathrm{~g} / \mathrm{L}$ de ácido acético. Isto acontece provavelmente devido ao caráter mais inerte do $\mathrm{N}_{2}$, quando comparado a gases oxidantes como o ar sintético e o $\mathrm{CO}_{2}$.

\section{DISCUSSÃO}

Em geral, ainda existem poucos trabalhos relacionados ao tratamento hidrotérmico com palha de cana, entretanto alguns resultados da literatura, realizados com bagaço de cana, mostram que o tratamento a altas temperatura $\left(>220^{\circ} \mathrm{C}\right)$ e baixos tempos de residência $(<2$ min.), associado a uma baixa carga de sólidos ( 5\%), resultam em aproximadamente $87 \%$ de rendimento de sacarificação e fermentação simultânea (Laser et al., 2002), entretanto, utilizar uma baixa carga de sólidos implica na utilização de grandes quantidades de água, grandes volumes reacionais e a fração líquida recuperada, rica em xilose, apresentaria baixas concentrações de açúcares C5, impedindo que a mesma pudesse ser utilizada diretamente em um processo de produção de álcool ou de produção de enzimas, necessitando obrigatoriamente de uma etapa de concentração.

Os resultados deste trabalho mostram que ao utilizar $10 \%$ de sólidos, temperaturas e tempo intermediários ( $165^{\circ} \mathrm{C}$ por $25 \mathrm{~min}$.), é possível atingir cerca de $74-78 \%$ de rendimento com baixa formação de inibidores, como furfural e HMF. Embora este tipo de tratamento remova parcialmente a fração hemicelulósica do material, a presença da lignina impede que rendimentos superiores a $90 \%$ sejam atingidos, provavelmente devido à baixa área de superfície específica encontrada nos materiais tratados, pois a lignina a altas temperatura adere a superfície das fibras de celulose impedindo que as mesmas fiquem exposta ao ataque enzimático.

\section{CONCLUSÕES}

Avaliando conjuntamente os resultados de hidrólise enzimático com os resultados de formação de inibidores, tem-se que a melhor condição de tratamento em termos de tipo de gás e pressão inicial de tratamento se dá ao utilizar 10 bar de nitrogênio, pela obtenção de um alto rendimento de hidrólise e uma menor formação de inibidores. Entretanto para uma otimização completa é necessário investigar os custos de processamento bem como outros parâmetros relevantes ao tratamento hidrotérmico, como, o $\mathrm{pH}$, a carga de biomassa, a agitação, a temperatura de tratamento e o tempo de residência, que serão investigados futuramente neste mesmo projeto.

\section{REFERÊNCIAS}

ADSUL, M.G., GHULE, J.E., SINGH, R., SHAIKH, H., BASTAWDE, K.B., GOKHALE, D.V., VARMA, A. J.,. Polysaccharides from bagasse: applications in cellulase and xilanase production. Carbohydr. Polym. 57, 67-72, 2004. 
ALVIRA, P., TOMÁS-PEJÓ, E., BALlESTEROS, M., NEGRO, M. J.. Pretreatments Technologies for an efficient bioethanol production process based on enzymatic hydrolysis: A review. Bioresource Technology 101: 4851-4861, 2010.

BRODEUR, G., YAU, E., BADAL, K., COLLIER, J., RAMACHANDRAN, K. B., RAMAKRISHNAN, S., Chemical and Physicochemical Pretreatment of Lignocellulosic Biomass: A Review. Enzyme Research, 2011.

CHENG, K.K., CAI, B.Y., ZHANG, J.A., LING, H.Z., ZHOU, Y.J., GE, J.P., XU, J.M.,. Sugarcane bagasse hemicellulose hydrolysate for ethanol production by acid recovery process. Biochem. Eng. J. 38, 105-109, 2008.

HERNÁNDEZ-SALAS， J.M., VILLA-RAMÍREZ， M.S., VELOZ-RENDÓN， J.S., RIVERA-HERNÁNDEZ， K.N., GONZÁLEZ-CÉSAR， R.A., PLASCENCIAESPINOSA, M.A., Trejo-Estrada, S.R., Comparative hydrolysis and fermentation of sugarcane and agave bagasse. Bioresource Technology. 100, 1238-1245, 2009.

LASER M, SCHULMAN D, ALLEN SG, LICHWA J, ANTAL MJ, LYND LR. A comparison of liquid hot water and steam pretreatments of sugar cane bagasse for bioconversion to ethanol. Bioresource Technology; 81, 33-44, 2002.

MARTíNEZ, E.A., SILVA, S.S., SILVA, J.B.A., SOLENZAL, A.I.N., FELIPE, M.G.A.,. The influence of $\mathrm{pH}$ and dilution rate on continuous production of xylitol from sugarcane bagasse hemicellulosic hydrolysate by C. Guilliermondii. Process Biochem. 38, 1677-1683, 2003.

Mc MILLAN, J.D., Pretreatment of lignocellulosic biomass. In: Himmel, M.E., Baker, J.O., Overend, R.P. (Eds.), Enzymatic Conversion of Biomass for Fuels Production. American Chemical Society, Washington, DC, pp. 292-324, 1994.

PANDEY, A., SOCCOL, C.R., NIGAM, P., SOCCOL, V.T., Biotechnological potential of agro-industrial residues. I. Sugarcane bagasse. Bioresour. Technol. 74 (2), 69-80, 2000.

SARKO, A. Cellulose- How much do we know about this its structure? In: Wood and Cellulosics: Industrial Utilization. Biotechnology, Structure and Porperties. John Wiley \& Sons, New York, 1997. 